NASA Technical Memorandum 4328

$$
\begin{gathered}
1 N-C 7 \\
40354 \\
P .19
\end{gathered}
$$


NASA Technical Memorandum 4328

\section{Preliminary Flight Evaluation of an Engine Performance Optimization Algorithm}

H. H. Lambert and G. B. Gilyard

Dryden Flight Research Facility

Edwards, California

J. D. Chisholm

McDonnell Douglas Corporation

McDonnell Aircraft Company

St. Louis, Missouri

L. J. Kerr

Pratt \& Whitney

Government Engine and Space Business

West Palm Beach, Florida

\section{N/SA}

National Aeronautics and

Space Administration

Office of Management

Scientific and Technical

Information Program

1991 



\title{
PRELIMINARY FLIGHT EVALUATION OF AN ENGINE PERFORMANCE OPTIMIZATION ALGORITHM
}

\author{
H.H. Lambert* and G.B. Gilyard** \\ NASA Dryden Flight Research Facility \\ Edwards, California \\ J.D. Chisholm ${ }^{\dagger}$ \\ McDonnell Aircraft Company \\ McDonnell Douglas Corporation \\ St. Louis, Missouri \\ L.J. Kerr ${ }^{\ddagger}$ \\ Pratt \& Whitney \\ Government Engine and Space Business \\ West Palm Beach, Florida
}

\begin{abstract}
The initial flight test evaluation phase of the performance seeking control (PSC) algorithm has been completed for one engine, subsonic, part power, and military power operation on an F-15 aircraft, using a PW1128 engine. The algorithm is designed to optimize the quasi-steady-state performance of an engine for three primary modes of operation: the minimum fuel, the minimum fan turbine inlet temperature (FTIT), and the maximum thrust modes. The minimum fuel mode is designed to minimize thrust-specific fuel consumption during cruise conditions. The minimum FTIT mode is designed to extend the turbine life by decreasing the FTIT during cruise and accelerating flight conditions. The maximum thrust mode is designed to maximize net propulsive force at military power. Decreases in thrust-specific fuel consumption of approximately 1 percent have been measured in the minimum fuel mode; integrated over the life of the aircraft and fleet size, these fuel savings are significant. Decreases of up to approximately $100^{\circ} \mathrm{R}$ in FTIT were measured in the minimum FTIT mode. Temperature reductions of this magnitude are significant and would more than double engine life if FTIT were the only factor. Thrust increases of up to approximately 12 percent were measured in the maximum thrust mode. The system dynamics of the closed-loop algorithm operation appear good. The preliminary flight phase has provided a general validation of the

\footnotetext{
"Aerospace Engineer. Member AIAA.

**Aerospace Engineer.

'Propulsion Engineer. Member ASME.

'Systems Engineer.

Copyright (C)1991 by the American Institute of Aeronautics and Astronautics, Inc. No copyright is asserted in the United States under Title 17 , U.S. Code. The U.S. Government has a royalty-free license to exercise all rights under the copyright claimed herein for Governmental purposes. All other rights are reserved by the copyright owner.
}

PSC technology which can provide significant benefits to the next generation of fighter and transport aircraft.

\section{Nomenclature}

AAHT high-pressure turbine area component deviation parameter, in ${ }^{2}$

AJ nozzle throat area, in ${ }^{2}$

$A J N L \quad$ effective nozzle throat area, in ${ }^{2}$

$B L D \quad$ bleed air flow, $\mathrm{lb} / \mathrm{sec}$

CEM compact engine model

CIM compact inlet model

CIVV compressor inlet variable guide vane, deg

CPSM compact propulsion system model

DEEC digital electronic engine control

DEHPT high-pressure turbine component deviation parameter, percent

$D E L P T \quad$ low-pressure turbine component deviation parameter, percent

DINL inlet drag, lb

DNOZ nozzle drag, $\mathrm{lb}$

$D R A M \quad$ ram drag, lb

$D W F A N$ fan airflow component deviation parameter, $\mathrm{lb} / \mathrm{sec}$

$D W H P C$ high-pressure compressor airflow component deviation parameter, $\mathrm{lb} / \mathrm{sec}$

EMD engine model derivative

EPR engine pressure ratio, PT6/PT2

$F \quad$ steady-state variable model sensitivity matrix 


$\begin{array}{llll}F G & \text { gross thrust, lb } & y_{p} & \begin{array}{c}\text { vector of output variables in the linear } \\ \text { programming problem }\end{array} \\ F N & \text { net thrust, lb } & \text { Prefix } & \\ F N P & \text { net propulsive force, lb } & \Delta & \text { perturbation } \\ F T I T & \text { fan turbine inlet temperature, }{ }^{\circ} \mathrm{R} & \partial & \text { partial } \\ \text { HIDEC } & \text { highly integrated digital electronic control } & \text { Suffix, PW1128 engine station numbers, ref. Fig. } 3 \\ H P X & \text { power extraction, hp } & 2 & \text { fan inlet } \\ h & \text { altitude } & 2.5 & \text { compressor inlet } \\ M & \text { Mach number } & 3 & \text { compressor discharge } \\ \text { MIL } & \text { military } & 4 & \text { high-pressure turbine inlet } \\ N 1 & \text { fan rotor speed, rpm } & 6 & \text { afterburner discharge inlet } \\ N 1 C 2 & \text { fan rotor speed, corrected to station } 2, \text { rpm } & 6 & \text { nozzle throat discharge } \\ N 2 & \text { compressor rotor specd, rpm } & 7 & \text { Superscript } \\ P_{a m b} & \text { ambient pressure, lb/in } & T & \text { transpose } \\ P B & \text { burner pressure, lb/in } & & \end{array}$

\section{Introduction}

The increasing use of digital engine control has opened up the possibility of significantly improving the performance of aircraft turbofan engines. Control laws for current generation engines are based on classical control theory and empirically developed schedules that must accommodate a wide range of engine health and off-nominal operation. These schedules are compromised to account for variations in manufacturing tolerances, the uncertainty associated with engine deterioration, and other off-nominal behavior of gas turbine components for a specific engine. Performance improvements can be achieved using sophisticated control algorithms designed to recover the full performance potential of the propulsion system.

The NASA Dryden Flight Research Facility has developed, flight tested, and evaluated propulsion system improvements on the F-15 airplane for over a decade. The F-15 flight research program included the first flight implementation of a full authority digital electronic engine control (DEEC), ${ }^{1,2}$ followed by flight test of an F100 engine model derivative (EMD), ${ }^{3}$ and most recently implemented a highly integrated digital electronic control (HIDEC) on the engine. 4,5 The F100 EMD program demonstrated the performance benefits resulting from improved fan, turbine, and afterburner design. The HIDEC program demonstrated performance improvements such as increased thrust and extended turbine life for a nominal engine. Favorable results from the HIDEC study supported further research into adaptive optimization algorithms.

There is considerable interest in developing real-time performance optimization technology for application to highspeed commercial transport and advanced fighter designs. The Air Force has funded an independent performance seeking control study. ${ }^{6}$ The performance benefits demonstrated on the F-15 HIDEC research vehicle, coupled with the Air 
Force performance seeking control study, prompted the performance seeking control (PSC) program, currently under flight test evaluation at the NASA Dryden Flight Research Facility. The objective of PSC is to adaptively optimize the near-steady-state performance of an aircraft-propulsion system in real time.

The PSC algorithm has three primary modes of operation: the minimum fuel, the minimum fan turbine inlet temperature (FTIT), and the maximum thrust modes. The minimum fuel mode is designed for cruise conditions, the minimum FTIT mode is designed for both cruise and accelerating flight conditions, and the maximum thrust mode is primarily intended for use during accelerating flight conditions. The minimum fuel mode minimizes fuel flow while maintaining constant net propulsive force (FNP) throughout the maneuver, or effectively minimizes thrust-specific fuel consumption (TSFC). During cruise conditions, the minimum FTIT mode lowers the FTIT while maintaining constant FNP throughout the maneuver. During accelerating flight conditions, the minimum FTIT mode lowers the FTIT while allowing FNP to increase with flight condition. The maximum thrust mode maximizes FNP at military (MIL) power settings.

The PSC algorithm optimizes the propulsion performance during quasi-steady-state mancuvers by applying trims to the propulsion system. The trim values are determined from an onboard, real-time optimization process. The PSC control law includes an estimation process, a modeling process, and an optimization process. The estimation process uses a Kalman filter to estimate component deviation parameters from flight measurements. The component deviation parameters account for changing levels of engine health, engine-to-engine manufacturing differences, and off-nominal behavior of a specific engine. The modeling process uses linear and nonlinear models to estimate unmeasured engine parameters from flight measurements and the component deviation parameter estimates. The optimization process uses linear programming techniques to determine the optimal engine operating condition for the mode selected. The PSC algorithm relies heavily on accurate models of the inlet and engine system and estimates of unmeasured parameters. Before implementation, the algorithm was tested extensively with simulated data. The parameter estimation and modeling processes have undergone preliminary evaluation using flight test data. ${ }^{7}$ Results indicate the PSC estimation algorithm provides reasonable estimates of the variables needed to optimize the engine operation.

Preliminary flight testing of the various PSC modes was conducted using one of the two F-15 engines. This paper presents qualitative results for the PSC modes at the PSC model design condition and other selected conditions. Flight testing has been restricted to the subsonic flight envelope and for throttle settings up to MIL power. Results for the steady-state and dynamic behavior of the control law and the performance benefits are discussed.

\section{Airplane and Engine Description}

The PSC program has been implemented on the NASA F-15 research airplane (Fig. 1), which is a modified high-performance aircraft capable of speeds in excess of Mach 2.0. The F-15 aircraft is powered by two PW 1128 afterburning turbofan engines. The aircraft has been modified with a digital electronic flight control system. Additional information on the F-15 aircraft is found in Ref. 3.

The PW1128 engine is a moderate-bypass ratio, twinspool, afterburning turbofan technology demonstrator, derived from the F100-PW-100 engine. The engine is controlled by a full-authority DEEC that is similar to the current production F100 engine controller. The DEEC provides both open-loop scheduling and closed-loop feedback control of corrected fan speed $(N 1 C 2)$ by way of the fuel flow $(W F)$ and engine pressure ratio $(E P R)$ by way of the nozzle throat area $(A J)$. The compressor inlet variable guide vane $(C I V V)$ and rear compressor variable vane $(R C V V)$ positions are scheduled on rotor speeds by way of open-loop control. The DEEC software has been modified to accommodate PSC; however, the normal DEEC control loops (that is, $N 1 C 2$ and $E P R$ ) have not been modified. A more detailed description of the PW1128 engine is in Ref. 2.

A diagram of the PW1128 engine is shown in Fig. 2. The locations of the DEEC instrumentation, the DEEC calculated parameters, and the parameters estimated by PSC are indicated. Fan airflow (WCFAN) and engine face total pressure $(P T 2)$ are independently modelled by both the DEEC and PSC control laws. The PSC algorithm requires only conventional DEEC instrumented parameters as inputs and estimates other necessary parameters within the algorithm. The engine instrumentation and a wide range of internal PSC algorithm parameters are sampled at $20 \mathrm{~Hz}$. The airdata are obtained from the F-15 production side probes. The algorithm corrects the data for position error and location effects. The airdata are recorded at $20 \mathrm{~Hz}$. All data are recorded on a pulse code modulation (PCM) system.

\section{Performance Seeking Control Law Algorithm}

The general structure of the PSC algorithm involves calculating optimal control trim commands for a propulsion system model that is continuously updated. A flow diagram of the algorithm is given in Fig. 3. The control law has estimation, modeling, and optimization processes. The estimation process is a Kalman filter estimation of five component deviation parameters designed to account for the off-nominal behavior of the engine during flight. The second step formulates and uses the compact propulsion system model (CPSM) to estimate unmeasured engine outputs, 
such as component stall margins, required for an optimal solution.

Flight measurements are used to look up model data and as direct inputs to both the Kalman filter and the CPSM. The component deviation parameter estimates are also input to the CPSM. The estimates cause the CPSM outputs to more accurately reflect the actual engine operating condition. A propulsion system matrix (PSM) derived from the CPSM is the basis of the optimization process. Because of the nonlinearity of the problem, each set of optimal trims does not necessarily represent the final solution. The final solution must be converged to over time. Additional information on the structure and design of the PSC algorithm is available in Ref. 8. The PSC algorithm is an outer-loop controller and does not effect the normal engine DEEC control loops $N 1 C 2$ and $E P R$.

\section{Kalman Filter}

The first step in the PSC algorithm is to identify the offnominal characteristics of the engine when operating at or near steady-state conditions. This is done by estimating five component deviation parameters with a Kalman filter: the low- and high-pressure turbine efficiency component deviation parameters (DELPT and DEHPT), the fan and high-pressure compressor airflow component deviation parameters ( $D W F A N$ and $D W H P C$ ), and the high-pressure turbine area component deviation parameter $(A A H T)$. The $D E L P T$ and DEHPT are related to the changes from nominal in the low- and high-pressure turbine efficiency. The $D W F A N$ and $D W H P C$ are related to the changes from nominal in fan and high-pressure compressor airflow. The $A A H T$ is related to changes from nominal in the highpressure turbine area. These parameters are used to adjust the nominal CPSM to match the actual engine operating condition. The state variable model (SVM) is used in the design and implementation of the Kalman estimator. The SVM is a piecewise linear model covering the entire range of engine operation at Mach 0.90 at an altitude of $30,000 \mathrm{ft}$, at standard day conditions. The estimator consists of a statespace perturbation model, an associated table of steady-state trim values for all the engine variables in the model, and some extended nonlinear calculations. The SVM model data are a function of PT4 and PT6. The state, control, and measurement vectors are defined as

$$
\begin{aligned}
& x=[N 1 N 2 \text { TMT DEHPT DELPT } \\
& D W F A N \text { DWHPC AAHT] }{ }^{T} \\
& u=\left[\begin{array}{llll}
W F & A J C I V V & R C V V H P X & B L D
\end{array}\right]^{T} \\
& y=\left[\begin{array}{lllllll}
\text { PT6 PT FTIT N1 N2 } & \text { F }
\end{array}\right.
\end{aligned}
$$

The locations of the engine parameters are shown in Fig. 2. Values for the following measurements and control variables are taken directly from flight data: $N 1, N 2, P B$, FTIT, PT6, WF, AJ, CIVV, and RCVV. The PT4 is modelled as a function of $P B, H P X$ is modelled as a func- tion of $N 2$, and $B L D$ is modelled as a function of Mach and altitude. Additional engine and flight parameters are used indirectly by the Kalman filter to calculate other engine variables and to transform the engine data to the SVM design condition of Mach 0.90 at an altitude of 30,000 ft. Multipliers that are functions of $P T 2$ and TT2 are used to transform the measured and calculated engine variables to different flight conditions. Additional information on the Kalman filter is found in Refs. 8 and 9.

\section{Compact Propulsion System Model}

The second step in the PSC algorithm is formulation of the CPSM. The CPSM combines two smaller compact models, the compact engine model (CEM) and the compact inlet model (CIM), that together model the propulsion system and form the basis for the optimization process.

\section{Compact Engine Model}

The CEM consists of a linear steady-state perturbation model, referred to as the steady-state variable model (SSVM), and follow-on nonlinear calculations, including nozzle effects. The SSVM is of the form

$$
y_{m}=F u_{m}
$$

It has a design condition of Mach 0.90 at an altitude of $30,000 \mathrm{ft}$, but has been transformed to a sea level static reference condition for implementation. The $u_{m}$ and $y_{m}$ variables represent the SSVM control input and measurement vectors, respectively. They are defined as

$$
\begin{aligned}
& u_{m}=[\text { WF PT6 CIVV RCVV HPX BLD DEHPT } \\
& \text { DELPT DWFAN DWHPC AAHT] }]^{T}
\end{aligned}
$$

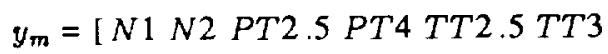

$$
\begin{aligned}
& \text { TT4 FTIT TT6 WCFAN WCHPC] }{ }^{T}
\end{aligned}
$$

The SSVM uses engine measurements for the following control inputs: $W F, P T 6, C I V V$, and $R C V V$. The HPX and $B L D$ are modelled as in the Kalman filter. The locations of the engine parameters are shown in Fig. 2. The Kalman filter estimates of the component deviation parameters are input to the SSVM calculation as part of the control vector. The control inputs are transformed to the SSVM sea level static reference condition using multipliers that are a function of PT2 and TT2. The SSVM provides estimates of the following variables at sea level static conditions: $N 1, N 2, A J, P T 2.5, P T 4, T T 2.5, T T 3, T T 4$, FTIT, TT6, WCFAN, and WCHPC. These estimates are then transformed to the original flight condition for use in the subsequent nonlinear CEM calculations. Several of the variables estimated by the SSVM are also instrumented: $N 1, N 2, A J$, and FTIT.

Following completion of the linear SSVM calculation, the nonlinear CEM estimates are calculated at the original 
flight condition. These variables include $P T 7, T T 7, F G$, $F N, D R A M, D N O Z, A J N L, S M F$, and $S M H C$. The nonlinear calculations use a combination of analytical equations and empirically derived data tables. They are based on both measured engine variables and SSVM estimates. If a variable is both measured and estimated, the flight measurement is used in the nonlinear calculations. The nonlinear calculations for $S M F, S M H C, A J N L$, and $F N$ are linearized with respect to $W F, P T 6, C I V V$, and $R C V V$ in real time. The partials produced are used in the follow-on optimization process. Additional information on the CEM calculations is available in Refs. 7 and 8.

\section{Compact Inlet Model}

The subsonic CIM consists of a nonlinear calculation of inlet drag (DINL) and the inlet PT2. At subsonic flight conditions, the nominal inlet schedules are optimal, and inlet geometry is not included in the PSC algorithm at subsonic conditions. Both DINL and the inlet PT2 are calculated as a function of Mach, WCFAN, and $P_{a m b}$. The PSC algorithm linearizes the $P T 2$ and DINL calculations with respect to $W C F A N$ in real time. The result is a linear steady-state perturbation model of the inlet. The $u_{i}$ and $y_{i}$ represent the control input and measurement vectors, respectively. At subsonic conditions, they are defined as

$$
\begin{aligned}
& u_{i}=\left[\begin{array}{l}
W C F A N
\end{array}\right] \\
& y_{i}=\left[\begin{array}{ll}
P T 2 & D I N L
\end{array}\right]^{T}
\end{aligned}
$$

Additional information on the CIM is available in Ref. 8.

\section{Optimization Process}

The subsonic phase of the PSC program optimizes the combined performance of the inlet and engine. The PSC algorithm uses linear programming techniques to determine the optimal engine control states. The linear programming optimization is based on a linear steady-state model referred to as the PSM. Linear models from the CEM and CIM are integrated to form the PSM. The PSM control and output vectors $u_{p}$ and $y_{p}$ are defined as

$$
\begin{aligned}
u_{p}= & {[W F P T 6 C I V V R C V V]^{T} } \\
y_{p}= & {[N 1 C 2 \text { N2WCFAN TT } 3 \text { FTIT }} \\
& \text { SMF SMHCAJ FNP }]^{T}
\end{aligned}
$$

The engine parameters are shown in Fig. 2.

The linear programming problem determines the optimum subject to a specific set of constraints. Each control and output variable has associated constraints that are used in the formulation of the linear programming problem. The constraints are functions of engine hardware, empirical data, and the desired goal of the optimization. The local opti- mal engine operating point is determined by iterating on the CPSM modeling-optimization process a specified number of times. The iterative process is referred to as inner looping. The component deviation parameters are assumed constant during the inner looping. Once the inner looping is completed, the engine interface logic determines the trims required to achieve the current optimal operating conditions. The current PSC configuration uses 12 iterations to determine each set of optimal trims. This iterative process takes approximately $5 \mathrm{sec}$.

\section{DEEC Interface and Supervisory Logic}

In addition to the PSC control law, the PSC system includes logic to interface with the DEEC, as well as logic to monitor and assure safe engine operation. The DEEC interface logic calculates the DEEC trims required to achieve the PSC optimal engine operating condition. Supervisory logic was developed to oversee the PSC operation. The engine operation is monitored to protect against fan stalls, and trims are modified if necessary. Supervisory logic also monitors the engine for transients resulting from PLA changes. The PSC algorithm is designed for quasi-steady-state engine operation. Therefore, PSC is suspended during engine transients and the engine reverts to baseline operation. The DEEC applies the PSC trims to the engine, subject to standard DEEC protection. The DEEC does not permit limits to be exceeded and, as such, overrides the PSC trims as necessary.

\section{Flight Test Results}

The three PSC modes have undergone preliminary subsonic flight testing. Maneuvers were flown on the F-15 aircraft to evaluate the performance benefits and the dynamic behavior of each mode. The engine data given in this paper were obtained from the following sources: the $W F$, $A J, C I V V, R C V V$, and PT6 were recorded from the right-hand test engine; the engine pressure ratio $(E P R)$ and $W C F A N$ data were recorded from the DEEC; the FNP was recorded from the PSC algorithm; and the TSFC was calculated postflight.

\section{Minimum Fuel Mode}

The minimum fuel mode is designed to minimize fuel flow (effectively $T S F C$ ) while maintaining constant $F N P$ during cruise conditions. The maneuvers flown consisted of flying at stabilized flight conditions with the PSC system engaged. The aircraft was allowed to stabilize at the cruise conditions before PSC was engaged. Data were recorded for approximately $2 \mathrm{~min}$ with PSC engaged. After $2 \mathrm{~min}$, the PSC system was disengaged, and another 2 min of data representing the baseline engine were recorded. The maneuvers were flown back-to-back to allow for direct comparisons by minimizing the effects of variations in the test day conditions. 
The minimum fuel mode was evaluated at two conditions: Mach 0.90 at an altitude of $30,000 \mathrm{ft}$ and a power level angle (PLA) of $40^{\circ}$, and Mach 0.88 at an altitude of $45,000 \mathrm{ft}$ and a PLA of $40^{\circ}$. The first condition represents the PSC model design point. The baseline performance schedules are efficient at Mach 0.90 at an altitude of $30,000 \mathrm{ft}$ and a PLA of $40^{\circ}$. Thus, small benefits were expected. It is, however, the point in the flight envelope where the estimation processes are expected to be the most accurate, as the linear models were derived at this condition. The second cruise condition of Mach 0.88 at an altitude of $45,000 \mathrm{ft}$ was selected to evaluate the mode operation at off-design conditions. This flight condition is near the maximum range cruise condition for the aircraft. To maintain constant flight conditions and constant test engine PLA during the maneuvers, the left throttle was modulated manually by the pilot to maintain Mach number.

Figure 4 shows the results for the cruise point of Mach 0.90 at an altitude of 30,000 ft. Time histories are given for the engine and linear programming control variables (WF, $A J, C I V V, R C V V$, and PT6), the algorithm performance variables (WF, FNP, and $T S F C$ ), and engine pressure ratio $(E P R)$ and WCFAN. The EPR is defined as $P T 6 / P T 2$. The PSC algorithm was engaged from 10 to $130 \mathrm{sec}$, as shown on the time histories. Dynamics caused by engaging PSC are apparent in both WF and FNP until approximately $75 \mathrm{sec}$. Thus, steady-state results pertain to the 75- to 130-sec part of the maneuver. The steady-state value of TSFC with PSC engaged was approximately 1.17 . The PSC algorithm held FNP to within \pm 2 percent of the initial value. Turning PSC off caused both WF and FNP to decrease in the steady state. The steady-state TSFC for the nominal engine was 1.18 , slightly greater than with PSC on. The modest decrease in TSFC was expected at this flight condition, as the baseline controller is efficient at Mach 0.90 at an altitude of $30,000 \mathrm{ft}$ and a PLA of $40^{\circ}$.

In general, the dynamic behavior of the engine was good (Fig. 4). Transient dynamics are observed until $75 \mathrm{sec}$ after PSC was engaged and are partially an artifact of the steady-state assumptions of the algorithm design. The $W F$, $P T 6$, and $A J$ showed slight variations during the remainder of the maneuver with PSC on, but the variations were not significant. The small decrease in TSFC was achieved by decreasing $W F$ to the engine, while trimming CIVV, $R C V V$, and $A J$ to maintain thrust. The key variables in the minimum fuel linear programming problem are $W F$ and $P T 6$. The PT6 is effected by $A J$. Decreasing $W F$ will decrease $F N P$, assuming all other variables are constant. Increasing $A J$ decreases $E P R$ and increases $W C F A N$, assuming all other variables are constant. At lower fan airflows, $W C F A N$ is more sensitive to the perturbation in $A J$ than at higher airflows. The FNP is affected by EPR and WCFAN, and the relative sensitivities of FNP to these parameters varies with engine operating condition. Decreasing either EPR or WCFAN while holding the other param- eter constant decreases FNP. In the minimum fuel mode, the PSC algorithm decreases $W F$ and uses PT6 to balance $E P R$ and WCFAN to hold the desired FNP. With the linear programming problem, the limiting constraints are

$$
\begin{aligned}
F N P & =\text { constant } \\
\Delta F N P & =\left(\partial F N P / \partial u_{p}\right) \Delta u_{p}
\end{aligned}
$$

For this particular test maneuver, PSC trims $A J$ to increase $W C F A N$ and decrease EPR to maintain FNP (Fig. 4). The $C I V V$ and $R C V V$ trims contribute to the $W C F A N$ increase, but their effect is small compared to that of $A J$. The small differences in the $W F, E P R$, and $W C F A N$ (Fig. 4) between PSC on and off indicate that the baseline schedules are efficient for this condition.

The results for the cruise maneuver at Mach 0.88 at an altitude of $45,000 \mathrm{ft}$ and a PLA of $40^{\circ}$ are shown in Fig. 5 . Time histories are given for the engine and linear programming control variables ( $W F, A J, C I V V, R C V V$, and $P T 6$ ), and algorithm performance variables (WF, FNP, and $T S F C$ ), and EPR and WCFAN. The PSC algorithm was engaged from 20 to $140 \mathrm{sec}$, as shown on the time histories.

The algorithm appeared to settle more quickly than at Mach 0.90 at an altitude of $30,000 \mathrm{ft}$, and the dynamics induced by engaging PSC are less pronounced. The engine response is slower at this condition than at Mach 0.90 at an altitude of $30,000 \mathrm{ft}$, and PSC is better able to track the engine dynamics. The PSC algorithm held FNP to within \pm 2 percent of the initial value. The steady-state value of TSFC with PSC engaged is approximately 1.04 at $125 \mathrm{sec}$. Between 125 and $140 \mathrm{sec}$, FNP is decreasing, causing the noticcable increase in TSFC (Fig. 5). The mean value for the $T S F C$ for the baseline engine is approximately 1.06, greater than with PSC on. The decrease in TSFC at this condition was achicved by the same mechanism described for the Mach 0.90 maneuver at $30,000 \mathrm{ft}$. Again, PSC decreases the $W F$ while trimming $A J$ to balance $E P R$ and $W C F A N$ to maintain $F N P$. For this maneuver, $A J$ was trimmed to increase $W C F A N$ and decrease EPR (Fig. 5).

The baseline performance schedules are less efficient at Mach 0.88 at an altitude of $45,000 \mathrm{ft}$ than at Mach 0.90 at an altitude of $30,000 \mathrm{ft}$. Thus, the steady-state differences with PSC on and off are more pronounced (Fig. 5). The relationship between the optimal and baseline engine operating conditions is a function of the baseline performance schedules, and would be different if the baseline schedules were defined differently.

The minimum fuel mode has performed as expected at most flight-throttle settings. The decreases in TSFC of 1 to 2 percent translate to significant fuel savings when integrated over the life of the aircraft and fleet. At some throttle settings, though, PSC appears to increase rather than decrease TSFC. The problem is currently under investigation. 


\section{Minimum FTIT Mode}

The minimum FTIT mode is designed to decrease the FTIT while maintaining FNP levels during both cruise and accelerating flight conditions. Engine turbine life can be expressed as turbine life exhaustion rate (TLER). Figure 6 shows TLER as a function of turbine temperature relative to the turbine melting temperature. The temperature ranges given represent typical engine operating temperatures. Overall turbine life is determined by the cumulative impact of TLER at different operating conditions over the aircraft mission. Lowering the FTIT decreases the TLER, resulting in extended turbine-combustor life.

The minimum FTIT mode was evaluated at Mach 0.90 at an altitude of $25,000 \mathrm{ft}$, MIL power, and over the Mach range of 0.75 to 0.95 at an altitude of $45,000 \mathrm{ft}$, MIL power. The maneuvers flown were similar to the maneuvers used to evaluate the minimum fuel mode. The aircraft was allowed to stabilize at the cruise condition with PSC off. The PSC algorithm was then engaged, and data were recorded for approximately $2 \mathrm{~min}$. The PSC was turned off, and data representing the baseline engine were recorded for another $2 \mathrm{~min}$. The maneuvers were flown back-to-back to minimize the effects of variations in the test day conditions.

Figure 7 shows the results for the Mach 0.85 cruise point at an altitude of $45,000 \mathrm{ft}$. Time histories are given for the engine and linear programming control variables $(W F, A J$, $C I V V, R C V V$, and $P T 6$ ), and the algorithm performance variables (FNP and FTIT), and EPR and WCFAN. The PSC was engaged from 10 to $125 \mathrm{sec}$, as shown on the time histories. The steady-state value of FTIT with PSC engaged was $2050^{\circ} \mathrm{R}$. The PSC algorithm increased FNP by 5 percent over the initial FNP, although the variation in $F N P$ with $P S C$ engaged was within \pm 1 percent. The steadystate value of FTIT for the baseline engine was $2150^{\circ} \mathrm{R}$. The PSC algorithm decreased the FTIT by $100^{\circ} \mathrm{R}$, and increased FNP slightly (Fig. 7). The FTIT decrease may have been greater if the algorithm had held the initial FNP value more closely.

With PSC engaged, $W F, C I V V$, and $R C V V$ were well behaved dynamically, while $A J$ exhibited a small amplitude oscillation of $\pm 5 \mathrm{in}^{2}$ (Fig. 7). The decrease in FTIT was achieved by trimming $W F, A J, C I V V$, and $R C V V$ to decrease WCFAN and thus the FTIT, while increasing the $E P R$ to maintain FNP. The algorithm decreased $A J$ to balance the WCFAN and EPR to maintain constant FNP.

Figure 8 shows predicted and flight-measured decreases in FTIT for various test points as a function of Mach and altitude. In all the cases, the throttle was at MIL power. In general, PSC performed as predicted in the minimum FTIT mode. Decreases of up to $100^{\circ} \mathrm{R}$ were measured at an altitude of $45,000 \mathrm{ft}$. Decreases of $20^{\circ} \mathrm{R}$ were mea- sured at Mach 0.90 at an altitude of 25,000 ft. Temperature reductions of this magnitude are significant and, as shown in Fig. 6, would double engine life if FTIT were the only factor. The goals for this mode were achieved as PSC obtained FTIT reductions while FNP was held constant.

\section{Maximum Thrust Mode}

The maximum thrust mode is designed to maximize FNP at MIL power. The maneuver flown consisted of stabilizing the engines at MIL power in a windup turn at Mach 0.50. The aircraft was then rolled to wings level and allowed to accelerate to Mach 0.95 at a constant altitude of $30,000 \mathrm{ft}$. The maneuver was executed twice, once with PSC off and once with PSC on. The accelerations were flown back-to-back to minimize the effects of variation in test day conditions.

Figure 9 shows time history comparisons of several engine variables for back-to-back maneuvers with PSC on and PSC off. Engine and linear programming control variables ( $W F, A J, C I V V, R C V V$, and $P T 6$ ), the performance variable (FNP), and EPR and WCFAN are given as a function of Mach number. The PSC algorithm increased FNP by 10 to 12 percent above the nominal thrust level, resulting in a substantial increase in acceleration. The PW1128 engine has conservative schedules because it was a technology demonstrator. The schedules would be more efficient in a production engine, and the engine manufacturer estimates that thrust increases of approximately 4 to 6 percent would be accrued with a production engine. The algorithm increased the FNP by increasing the $W F$ and $E P R$ (Fig. 9). The CIVV, RCVV, and WCFAN with PSC engaged were close to the nominal values, and $C I V V$ and $W C F A N$ were at physically limited values. The PSC algorithm decreased $A J$ and increased $E P R$ and $W F$ to maintain the maximum WCFAN (Fig. 9).

The optimal solution to the linear programming problem was bounded by different pairs of constraints as the maneuver progressed. Active linear programming problem constraints for the maneuver with PSC engaged are shown as a function of Mach number in Fig. 10. Active constraints included absolute minimum $A J$ and $S M H C$ constraints, absolute maximum $N 1$ and FTIT constraints, and a constraint on the maximum corrected PT6. The $A J$ constraint is an actual engine hardware constraint. The FTIT and $N 1$ constraints are obtained from the DEEC control laws. The $S M H C$ constraint was empirically derived from ground test data and simulation runs. Predominant constraints for this maneuver are the maximum $N 1$ and FTIT, and the minimum $A J$ limits.

Dynamically, the mode is stable with no oscillations present in the engine response parameters or control effectors. In general, the maximum thrust mode has performed well, demonstrating significant thrust increases at MIL power. 


\section{Concluding Remarks}

The initial fight test evaluation phase of the performance seeking control (PSC) algorithm has been completed for one engine, subsonic, part power, and military power operation on an F-15 aircraft. A qualitative evaluation of the three major modes of operation indicate that the algorithm is, in general, performing as designed. Thrust increases of up to 12 percent in the maximum thrust mode resulted in substantial increases in acceleration. Decreases of up to approximately $100^{\circ} \mathrm{R}$ in fan turbine inlet temperature (FTIT) were measured in the minimum FTIT mode. Temperature reductions of this magnitude are significant and would more than double engine life if FTIT were the only factor. Decreases of thrust-specific fuel consumption (TSFC) of approximately 1 percent have also been measured in the minimum fuel mode; integrated over the life of the aircraft and fleet size, these fuel savings are significant. Problems such as low-amplitude oscillations in the minimum FTIT mode and some TSFC discrepancies in the minimum fuel mode at selected throttle settings were noted. However, these problems are not major and are being resolved. The system dynamics of the closed-loop algorithm operation appear good.

This preliminary flight phase has provided a general validation of the PSC technology objectives. The PSC technology can provide significant benefits to the next generation of fighter and transport aircraft.

\section{References}

${ }^{1}$ Burcham, F.W., Jr., Myers, L.P., and Walsh, K.R., Flight Evaluation of a Digital Electronic Engine Control in a F-15 Airplane, NASA TM-84918, 1983.

${ }^{2}$ Digital Electronic Engine Control (DEEC) Flight Evaluation in an F-15 Airplane. Proceedings of a mini- symposium held at the NASA Dryden Flight Research Facility, Edwards, California, May 25-26, 1983, NASA CP-2298.

${ }^{3}$ Myers, Lawrence P., and Burcham, Frank W., Jr., Preliminary Flight Test Results of the F100 EMD Engine in an F-15 Airplane, NASA TM-85902, 1984.

${ }^{4}$ Baer-Riedhart, Jennifer L., and Landy, Robert J., Highly Integrated Digital Electronic Control-Digital Flight Control, Aircraft Model Identification and Adaptive Engine Control, NASA TM-86793, 1987.

${ }^{5}$ Highly Integrated Digital Electronic Control Symposium. Proceedings of a conference held at the NASA Dryden Flight Research Facility, Edwards, California, March 11-12, 1987, NASA CP-3024.

${ }^{6}$ Tich, Eric J., Shaw, Peter D., Berg, Donald F., Adibhatla, Shrider, Swan, Jerry A., and Skira, Charles A., "Performance Seeking Control for Cruise Optimization in Fighter Aircraft," AIAA-87-1929, June 1987.

${ }^{7}$ Maine, Trindel A., Gilyard, Glenn B., and Lambert, Heather H., A Preliminary Evaluation of an F100 Engine Parameter Estimation Process Using Flight Data, NASA TM-4216, 1990.

${ }^{8}$ Smith, R.H., Chisholm, J.D., and Stewart, J.F., "Optimizing Aircraft Performance with Adaptive, Integrated Flight/Propulsion Control," ASME-90-GT-252, presented at the Gas, Turbine and Aeroengine Congress and Exposition, Brussels, Belgium, June 1990.

${ }^{9}$ Luppold, R.H., Roman, J.R., Gallops, G.W., and Kerr, L.J., "Estimating In-Flight Engine Performance Variations Using Kalman Filter Concepts," AIAA-89-2584, July 1989.

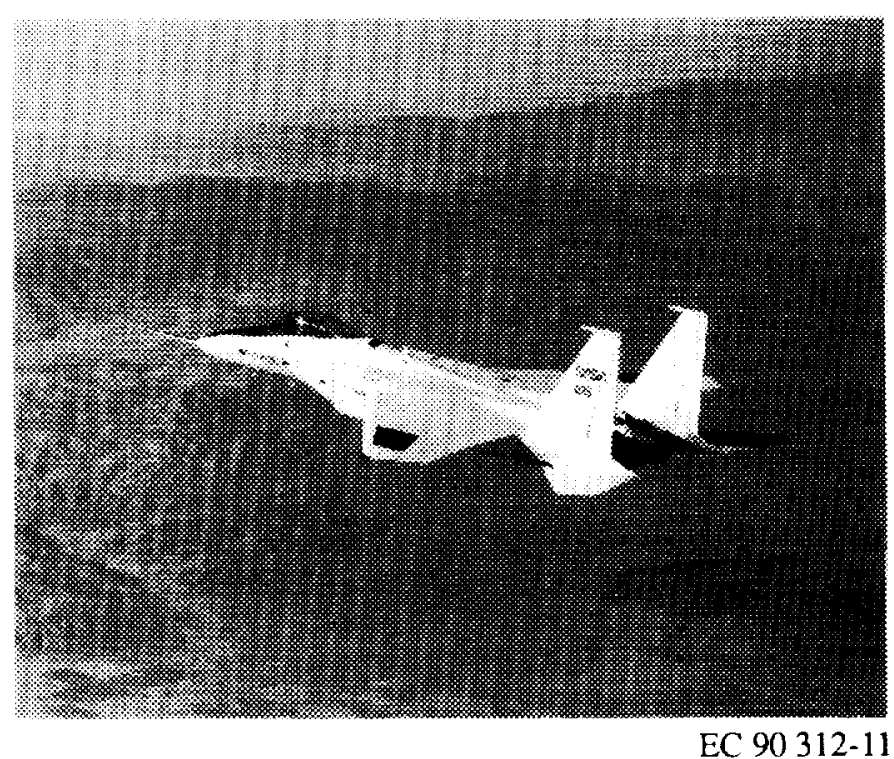

Fig. 1. The F-15 aircraft. 


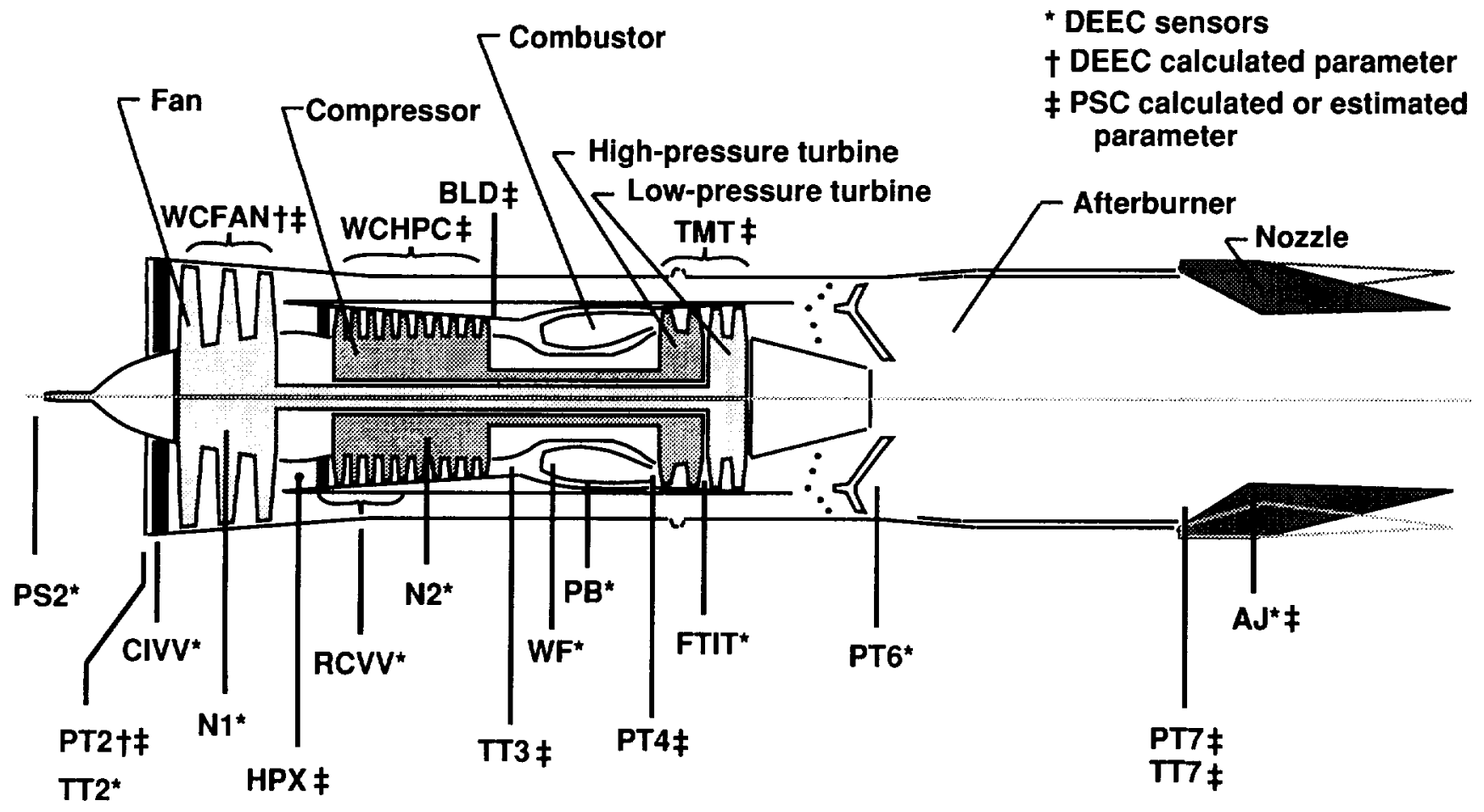

Fig. 2. PW1128 engine sensor and parameter locations.

$900 \uparrow 79$

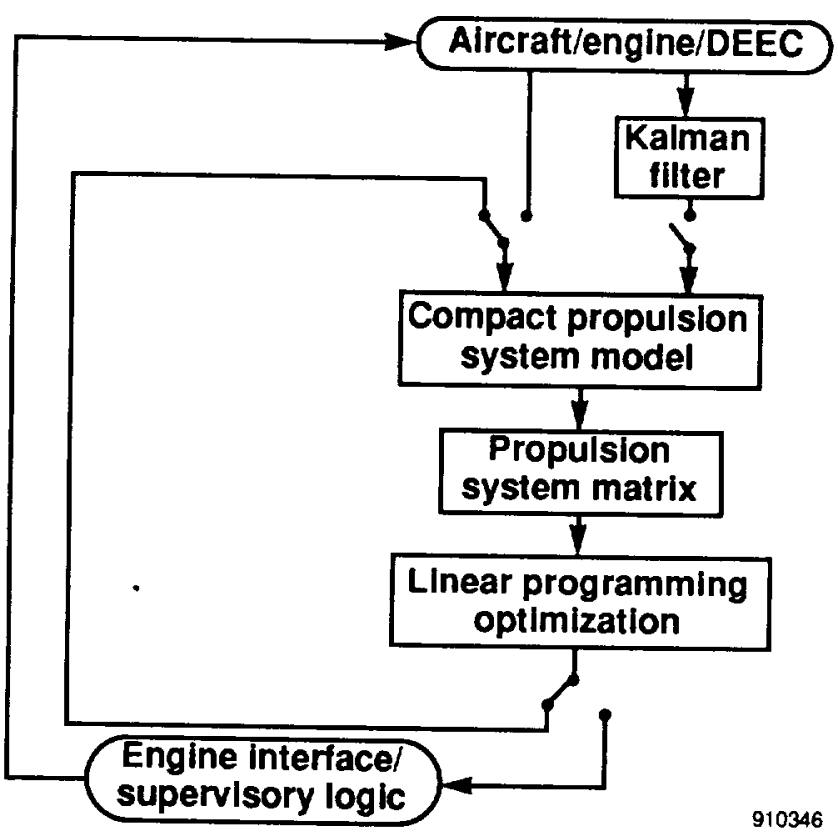

Fig. 3. Performance seeking control flow diagram. 


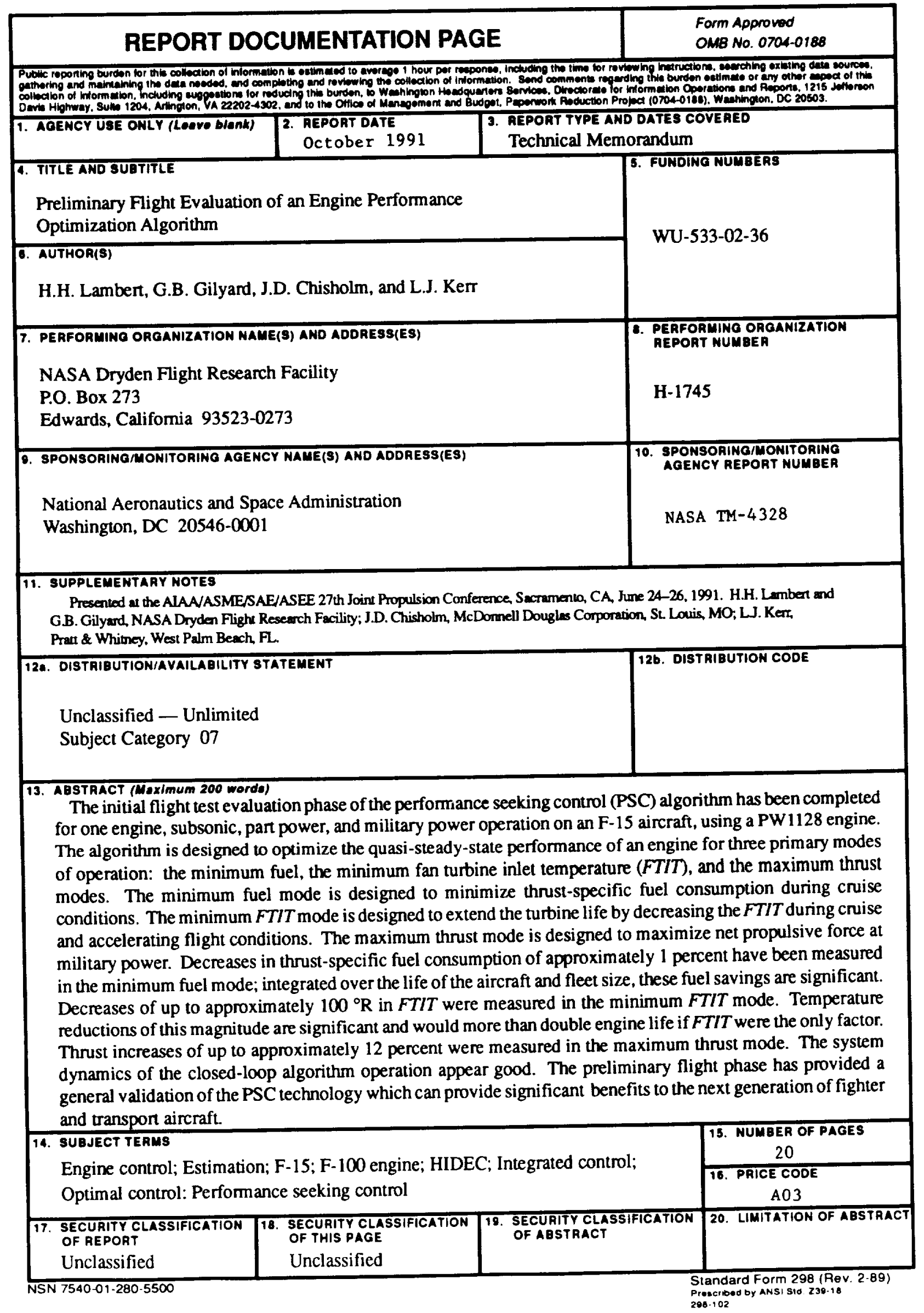




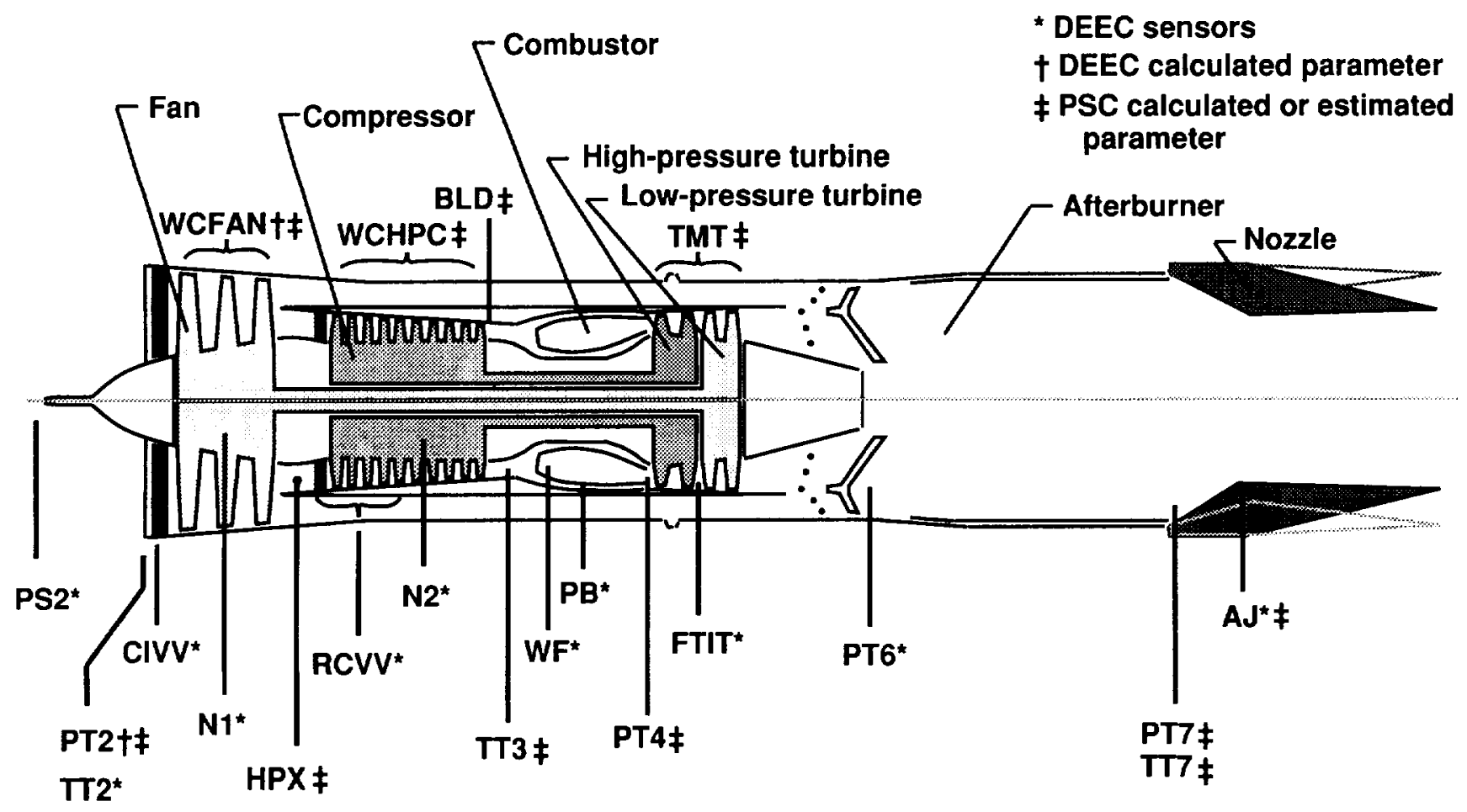

Fig. 2. PW1128 engine sensor and parameter locations.

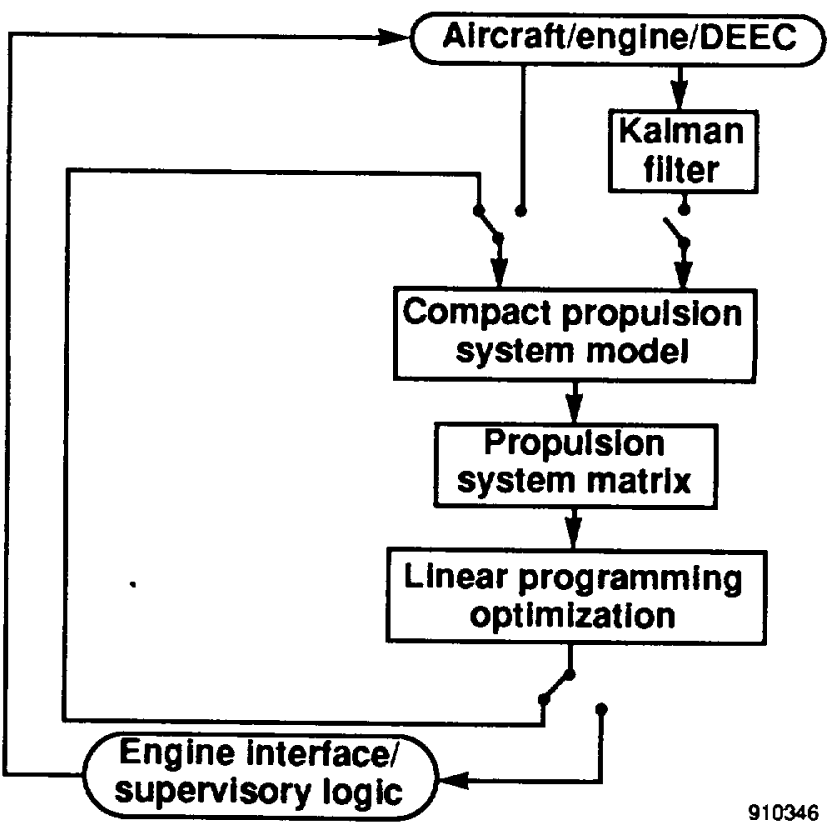

Fig. 3. Performance seeking control flow diagram. 

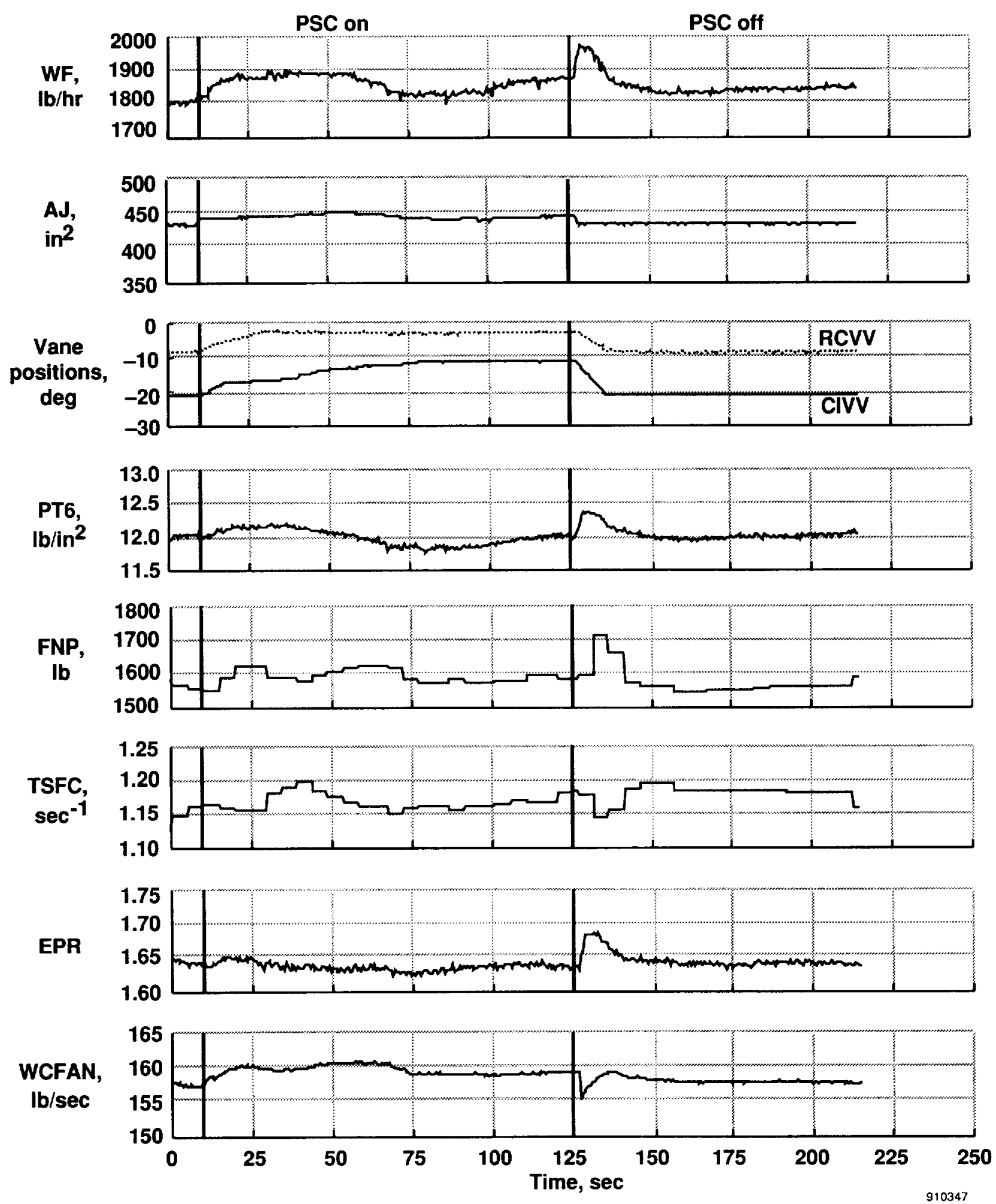

Fig. 4. Engine parameter time histories for minimum fuel mode evaluation; $M=0.90, h=30,000 \mathrm{ft}, \mathrm{PLA}=40^{\circ}$. 

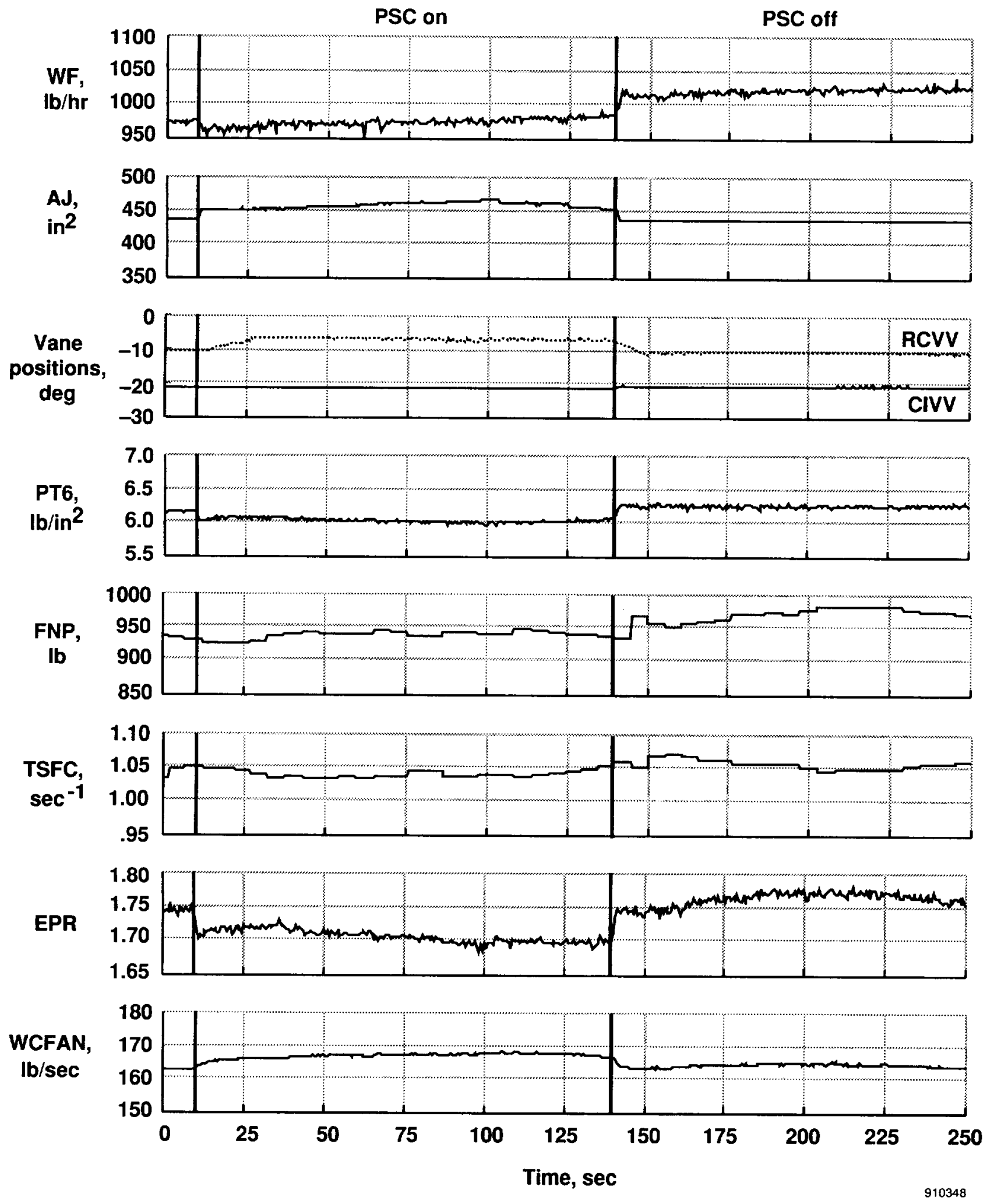

Fig. 5. Engine parameter time histories for minimum fuel mode evaluation; $M=0.88, h=45,000 \mathrm{ft}, \mathrm{PLA}=40^{\circ}$. 


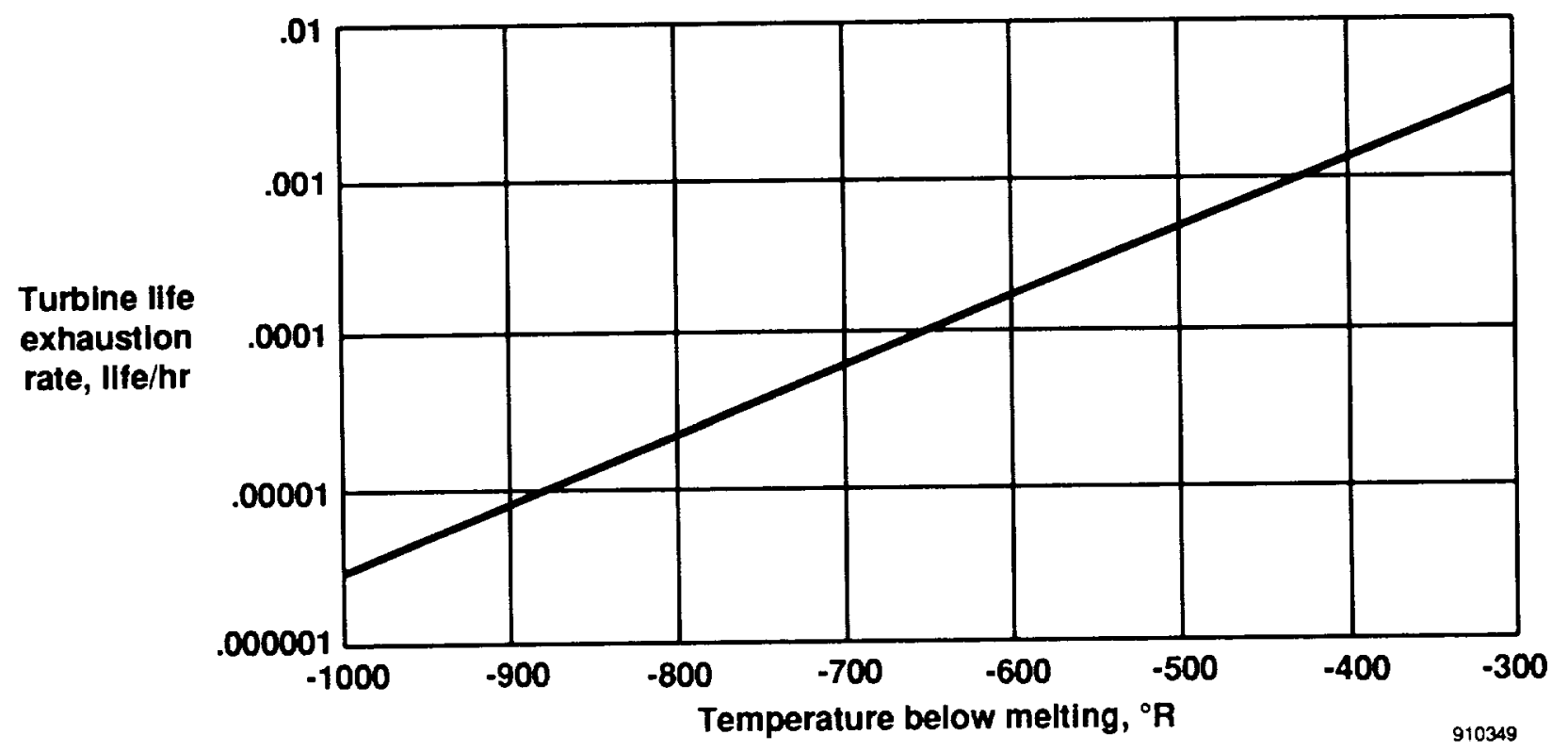

Fig. 6. Turbine life exhaustion rate as a function of turbine temperature. 

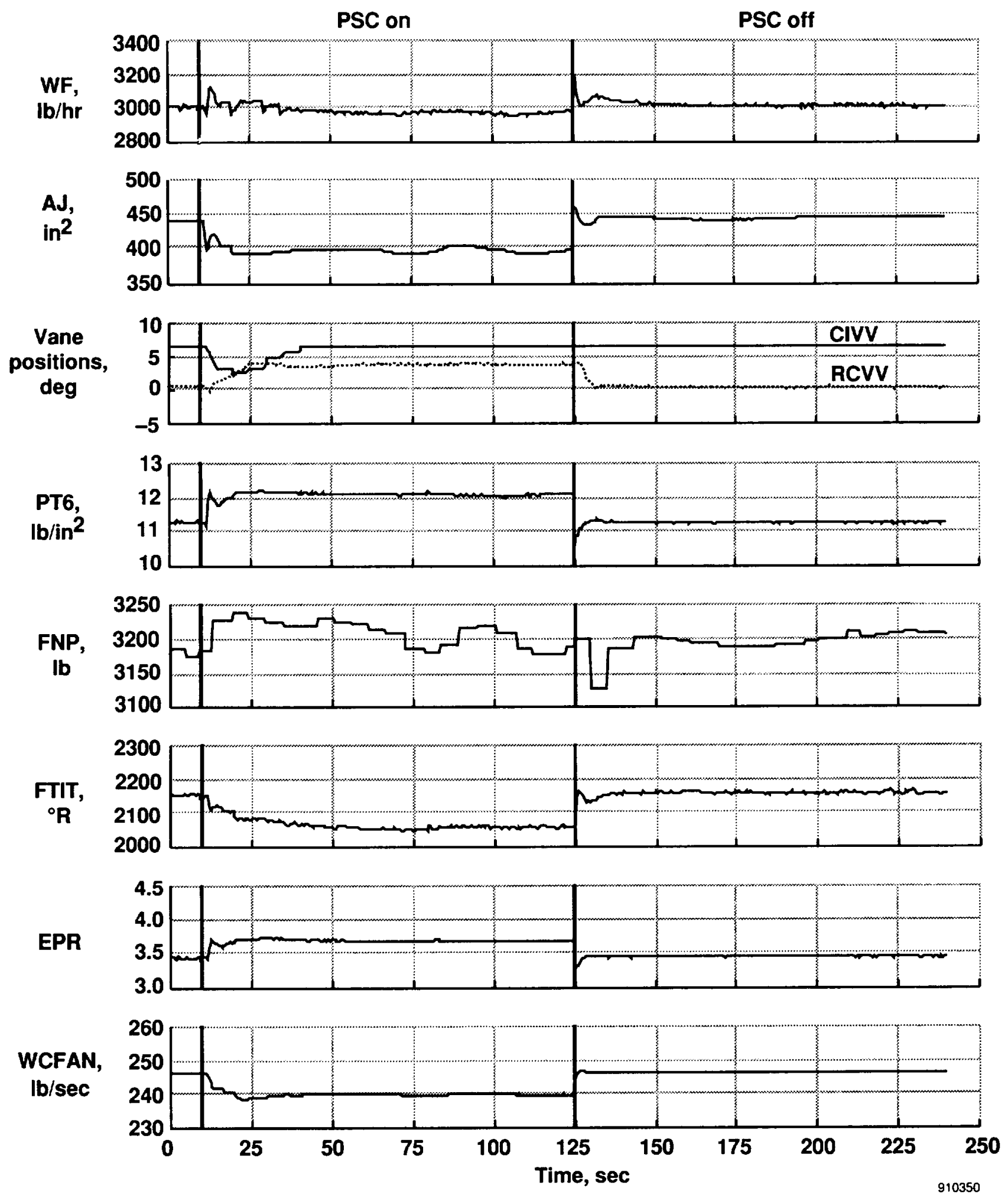

Fig. 7. Engine parameter time histories for minimum FTIT mode evaluation; $M=0.85, h=45,000 \mathrm{ft}$, MIL PLA. 


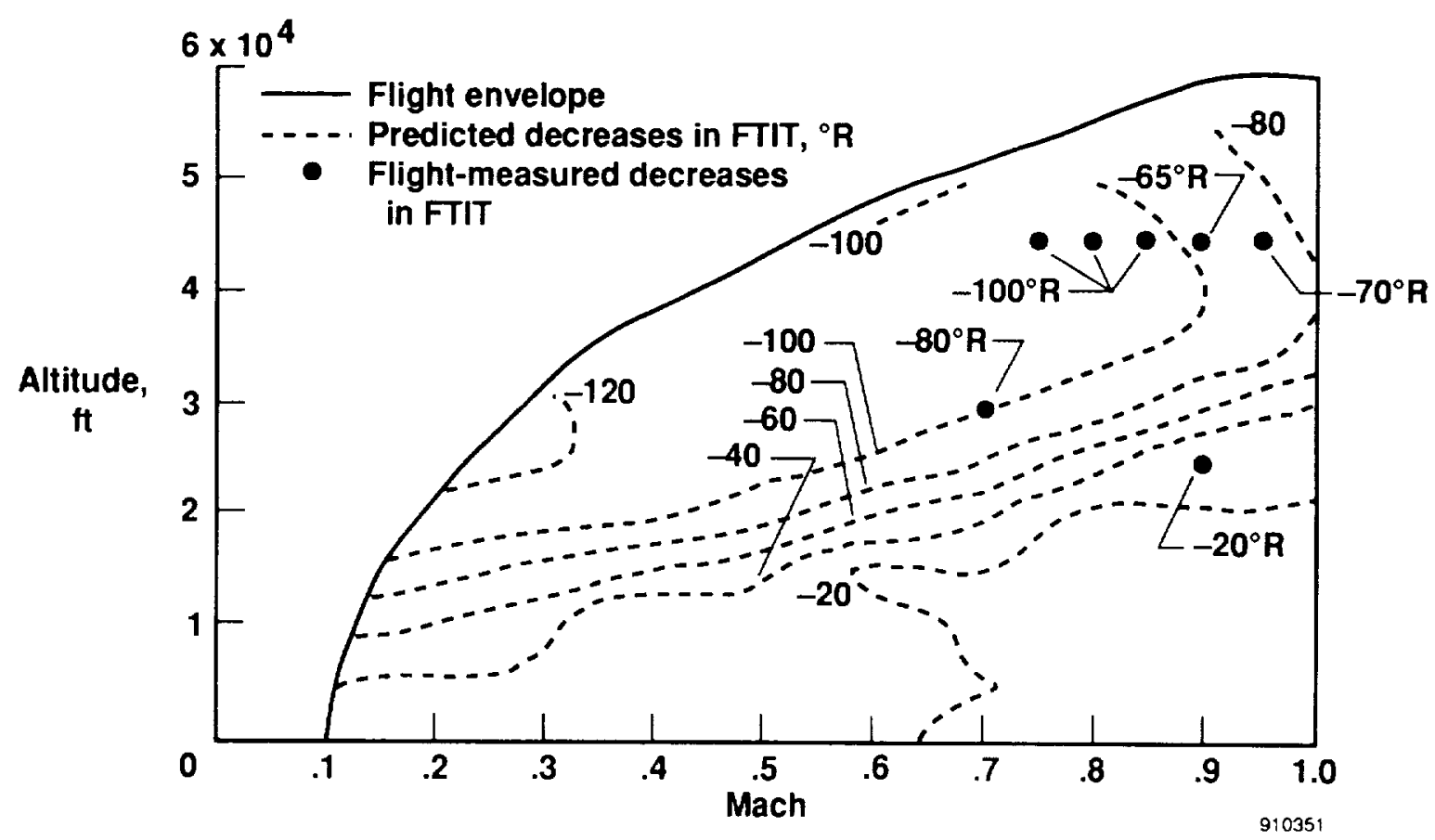

Fig. 8. Predicted and measured FTIT decreases as a function of flight condition. 

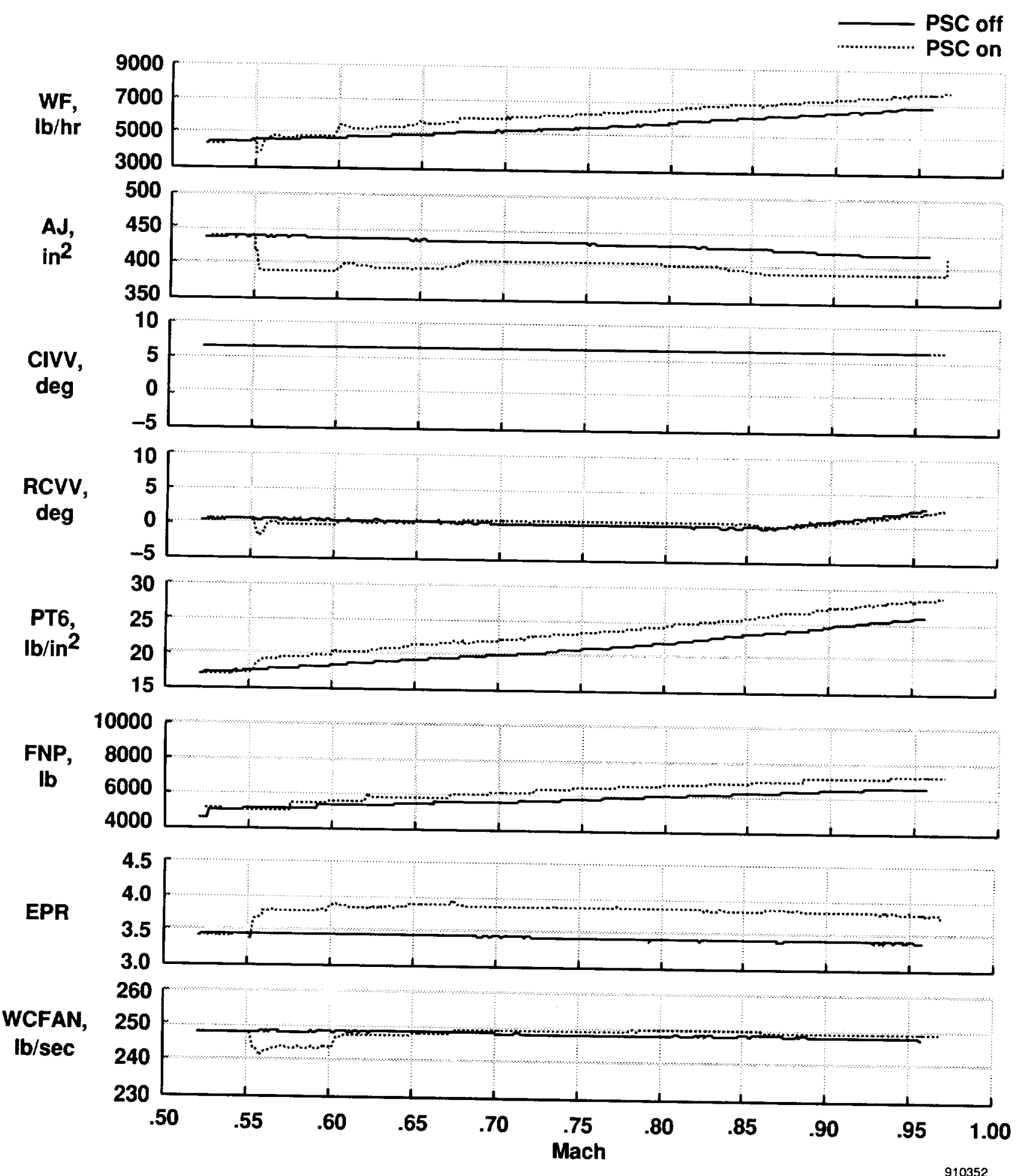
Fig. 9. Engine parameter time histories for maximum thrust mode evaluation; $M=0.50$ to $0.95, h=30,000 \mathrm{ft}$,
MIL PLA. 


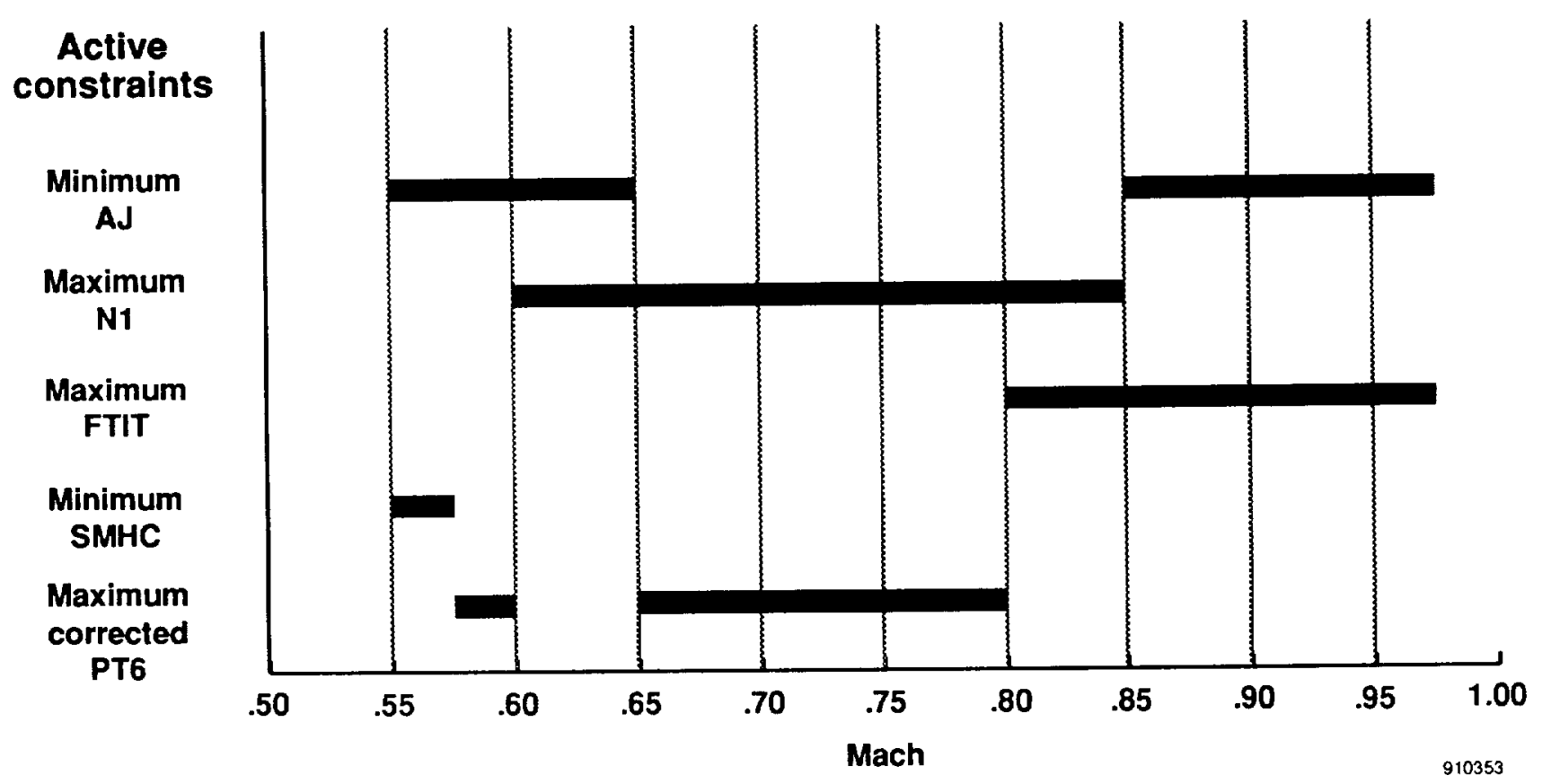

Fig. 10. Linear programming constraints for maximum thrust mode evaluation; $M=0.50$ to $0.95, h=30,000 \mathrm{ft}$, MIL PLA. 



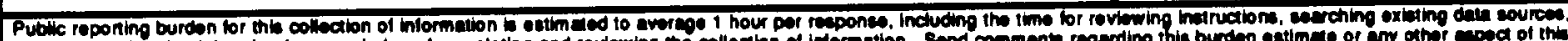

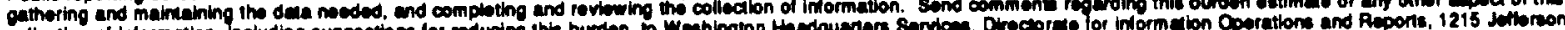

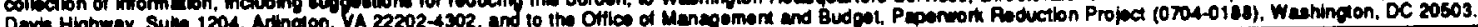

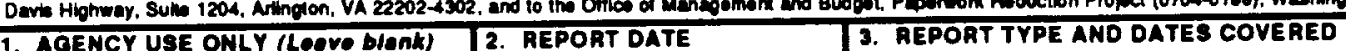

\begin{tabular}{l|l|l} 
1. AOENCY USE ONLY (Leevo blenk) & $\begin{array}{l}\text { 2. REPORT DATE } \\
\text { October } 1991\end{array}$ & $\begin{array}{l}\text { 3. REPOAT TYPE ANO DATES COV } \\
\text { Technical Memorandum }\end{array}$
\end{tabular}

4. TITLE AND SUBTITLE

5. FUNDINO NUWBERS

Preliminary Flight Evaluation of an Engine Performance

Optimization Algorithm

6. AUTHOA(S)

WU-533-02-36

H.H. Lambert, G.B. Gilyard, J.D. Chisholm, and L.J. Kerr

7. Perforling organization haMe(S) and addRess(ES)

PERFORMING ORGANIZATION

AEPORT NUMBER

NASA Dryden Flight Research Facility

P.O. Box 273

H-1745

Edwards, Califomia 93523-0273

9. SPONSORING/MONITOAING AGENCY MAME(S) AND ADDRESS(ES)

10. SPONSORING/MONITORING

AGENCY REPORT NUMBER

National Aeronautics and Space Administration

Washington, DC 20546-0001

NASA TM-4328

11. SUPPLEMENTARY NOTES

Presentod at the AIAAJASMESAE/ASEE 27th Joint Propulsion Conference, Sacramento, CA, Jume 24-26, 1991. H.H. Lamber and

GB. Gilyard, NASA Dryden Flight Research Facility; J.D. Chisholm. McDonnell Douglas Conporation, St. Louis, MO; LJ. Ker,. Pran \& Whitney, West Paim Beach, FL.

12a. DISTRIBUTIONIAVAILABILITY STATEMENT

12b. DISTRIBUTION CODE

Unclassified - Unlimited

Subject Category 07

13. ABSTRACT (Naxlmum 200 worde)

The initial flight test evaluation phase of the performance seeking control (PSC) algorithm has been completed for one engine, subsonic, part power, and military power operation on an F-15 aircraft, using a PW1128 engine. The algorithm is designed to optimize the quasi-steady-state performance of an engine for three primary modes of operation: the minimum fuel, the minimum fan turbine inlet temperature (FTIT), and the maximum thrust modes. The minimum fuel mode is designed to minimize thrust-specific fuel consumption during cruise conditions. The minimum FTIT mode is designed to extend the turbine life by decreasing the FTIT during cruise and accelerating flight conditions. The maximum thrust mode is designed to maximize net propulsive force at military power. Decreases in thrust-specific fuel consumption of approximately 1 percent have been measured in the minimum fuel mode; integrated over the life of the aircraft and fleet size, these fuel savings are significant. Decreases of up to approximately $100^{\circ} \mathrm{R}$ in FTIT were measured in the minimum FTIT mode. Temperature reductions of this magnitude are significant and would more than double engine life if $F T I T$ were the only factor. Thrust increases of up to approximately 12 percent were measured in the maximum thrust mode. The system dynamics of the closed-loop algorithm operation appear good. The preliminary flight phase has provided a general validation of the PSC technology which can provide significant benefits to the next generation of fighter and transport aircraft.

14. SUBJECT TERMS

Engine control; Estimation; F-15; F-100 engine; HIDEC; Integrated control; Optimal control: Performance seeking control

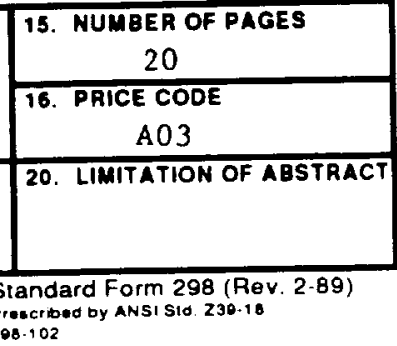

